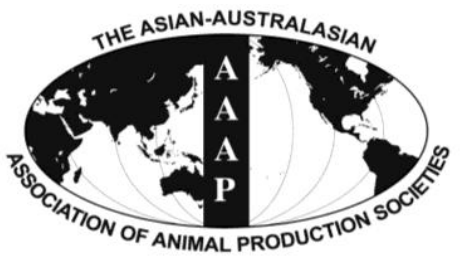

Asian-Aust. J. Anim. Sci.

Vol. 25, No. 12 : 1674-1680 December 2012

http://dx.doi.org/10.5713/ajas.2012.12503

www.ajas.info

pISSN 1011-2367 eISSN 1976-5517

\title{
A Whole Genome Association Study to Detect Single Nucleotide Polymorphisms for Blood Components (Immunity) in a Cross between Korean Native Pig and Yorkshire
}

\author{
Y.-M. Lee ${ }^{\text {a }}$, M. Alam ${ }^{\text {a }}$, B. H. Choi ${ }^{1}$, K.-S. Kim ${ }^{2}$ and J.-J. Kim* \\ School of Biotechnology, Yeungnam University, Gyeongsan, Korea
}

\begin{abstract}
The purpose of this study was to detect significant SNPs for blood components that were related to immunity using high single nucleotide polymorphism (SNP) density panels in a Korean native pig (KNP) $\times$ Yorkshire (YK) cross population. A reciprocal design of $\mathrm{KNP} \times \mathrm{YK}$ produced $249 \mathrm{~F}_{2}$ individuals that were genotyped for a total of 46,865 available SNPs in the Illumina porcine $60 \mathrm{~K}$ beadchip. To perform whole genome association analysis (WGA), phenotypes were regressed on each SNP under a simple linear regression model after adjustment for sex and slaughter age. To set up a significance threshold, $0.1 \%$ point-wise $\mathrm{p}$ value from $F$ distribution was used for each SNP test. Among the significant SNPs for a trait, the best set of SNP markers were determined using a stepwise regression procedure with the rates of inclusion and exclusion of each SNP out of the model at 0.001 level. A total of 54 SNPs were detected; 10, 6, 4, 4, 5, 4, 5, 10, and 6 SNPs for neutrophil, lymphocyte, monocyte, eosinophil, basophil, atypical lymph, immunoglobulin, insulin, and insulin-like growth factor-I, respectively. Each set of significant SNPs per trait explained 24 to $42 \%$ of phenotypic variance. Several pleiotropic SNPs were detected on SSCs 4, 13, 14 and 15. (Key Words: WGA, SNP, Immunity, Korean Native Pig, Yorkshire)
\end{abstract}

\section{INTRODUCTION}

Disease is one of the important factors in swine production. Due to large-scale intensive production systems, pigs are exposed on various pathogens that cause infectious diseases and pathological symptoms. Especially, porcine epidemic diarrhea (PED) and porcine reproductive and respiratory syndrome (PRRS) cause serious damage in pig farms each year. Once infected by the diseases, the pigs grow slow and yield low productivity, because the nutrients and energy for growth turn into use in defense of the pathogenic microorganisms, which can break out under insanitary environments in large-scale intensive production system (Coates et al., 1963; Roura et al., 1992).

Annual costs for treating epidemics are increasing in pork industry, causing loss of productivity and high

\footnotetext{
* Corresponding Author: Jong-Joo Kim. Tel: +82-53-810-3027, Fax: +82-53-801-3027, E-mail: kimjj@ynu.ac.kr

1 Animal Genomics and Bioinformatics Division, National Institute of Animal Science, Suwon, Korea.

${ }^{2}$ Department of Animal Science, Chungbuk National University, Cheongju, Korea.

a The two authors contributed equally to this work.

Submitted Aug. 14, 2012; Accepted Sept. 19, 2012; Revised Sept. 20, 2012
}

mortality rate. If a disease is heritable, i.e. genetic variation exists between individuals, selection of a pig that is resistant to a disease would enable its progeny to be also resistant, decreasing incidences of the disease and increasing productivity. Among selection methods for disease resistance, application of biomarkers, e.g. quantitative trait loci (QTL) or SNPs that are related to immune response, can be a good option to avoid damages caused by the disease, and several QTL studies were reported to find QTL for blood components that were related to immune response using microsatellites or high density SNP panels (Cho et al., 2011; Lu et al., 2011; Reiner et al., 2011).

To understand immunity responses, it is necessary to characterize blood components. The serum levels of cytokines and TLRs are important innate immune proteins, which indicate the level of disease resistance (Scheerlinck and Yen, 2005; Shinkai et al., 2006; Yao et al., 2008; Uenishi and Shinkai, 2009). IFNG and IL10 have immunomodulatory functions, possess antiviral activity, protect pig from diseases and modulate the survival time of infected animals (Scheerlinck and Yen, 2005; Danilowicz et al., 2008; Yao et al., 2008). IFNG and IL2 act 
synergistically and contribute to immune response. IFNG enhances IL1 secretion by priming monocytes to be more sensitive to an IL1-inducing stimulus (Kruse et al., 2008). IL10 is secreted from lymphocytes and monocytes (Scheerlinck and Yen, 2005).

In this study, we performed whole genome scans to find significant SNPs for blood components that are related to immunity using the Illumina porcine $60 \mathrm{~K}$ SNP chips in a $\mathrm{KNP} \times$ Yorkshire $\mathrm{F}_{2}$ cross population.

\section{MATERIALS AND METHODS}

\section{Animals and phenotypes}

Data were collected from the QTL experimental population that was produced by crossing Korean Native (KNP) boars and Yorkshire (YK) sows at National Livestock Research Institute (NLRI), Cheju, Korea. In the reciprocal cross design of the experiment, three $\mathrm{F}_{0}$ grand sires of KNP and $14 \mathrm{~F}_{0}$ grand dams of $\mathrm{YK}$ were mated. Among the $F_{1}$ offspring, five $F_{1}$ sires and $14 F_{1}$ dams were randomly chosen to produce $\mathrm{F}_{2}$ offspring. Another mating design comprised three $F_{0}$ grand sires of $Y K$ and nine $F_{0}$ grand dams of KNP to generate $F_{1} s$, among which nine $F_{1}$ sires and $29 \mathrm{~F}_{1}$ dams were randomly chosen. The two reciprocal matings produced $249 \mathrm{~F}_{2}$ individuals. The $\mathrm{F}_{2}$ individuals were raised under the similar feeding conditions in a private farm in Chungbuk province, and slaughtered at approximately $220 \pm 23 \mathrm{~d}$ of age.

Nine blood component measures that are related to serum immunity and hormones were measured in the $\mathrm{F}_{2} \mathrm{~s}$; neutrophil $(\mathrm{mg} / \mathrm{dl})$, lymphocyte $(\mathrm{mg} / \mathrm{dl})$, monocyte $(\mathrm{mg} / \mathrm{dl})$, eosinophil (mg/dl), basophil $(\mathrm{mg} / \mathrm{dl})$ ), atypical lymph $(\mathrm{mg} / \mathrm{dl})$, immuno globulin $(\mathrm{g} / \mathrm{dl})$, insulin (uIU/ml), and insulin-like growth factor-I (ng/ml). Table 1 depicted the mean and standard deviation for the respective blood component traits.

\section{Molecular data}

Using the Infinium HD Assay Ultra Protocol (Illumina), all of the $249 \mathrm{~F}_{2}$ animals were genotyped with the porcine 60k SNP bead chips (Illumina Inc., USA). Raw data were visualized and analyzed with the Genome Studio software (Illumina). Every SNP from the chip data was screened for GWA tests. Those SNPs on autosomal chromosomes were removed before WGA testing, which met the following three criteria; i) the number of genotype group with one or none (e.g. only AA genotypes and no $\mathrm{AB}$ or $\mathrm{BB})$, ii) with a minor allele frequency less than 0.05 , and iii) with the proportion of genotyped individuals less than 90\%. Among the 62,123 SNPs in the Illumina porcine chip, a total of 46,865 SNPs were selected for WGA tests.

\section{Statistical analysis}

A SAS GLM procedure (SAS version 9.1) was applied to pre-adjust the animal phenotypes before WGA testing. Sex and slaughter age were fitted as a fixed effect and a covariate, respectively. Then, the residuals of each phenotype were regressed for each SNP under a simple linear regression additive model. In the model, SNP genotypes with $\mathrm{AA}, \mathrm{AB}$ and $\mathrm{BB}$ were assigned as 1, 0, and -1 for the additive effect, respectively, reflecting a substitution effect of allele A on allele B. For significance threshold, $0.1 \%$ point-wise $\mathrm{p}$ value from $F$ distribution was applied for each SNP test.

Among the significant SNPs, the best set of markers for each trait was selected by applying a stepwise regression procedure (Neter et al., 1990), because some of the significant SNPs would yield redundant information due to linkage disequilibrium (LD) between closely linked SNPs, i.e. a non-random association between alleles of different SNPs. Inclusion and exclusion of each SNP out of the model was determined at 0.001 level.

The variation explained by each $\left(j^{\text {th }}\right) \operatorname{SNP}\left(S_{S N P j}^{2}\right)$ was calculated as $\sum_{i=1}^{3} \alpha_{i}^{2} f_{i}-\mu^{2}$, where $i$ denotes each genotype, $\alpha_{i}$ is allele substitution effect $(=-\hat{a}, 0$, and $+\hat{a}$ for $\mathrm{BB}, \mathrm{AB}$, and $\mathrm{AA}$, respectively, in which $\hat{a}$ was estimated from the simple regression analysis for the SNP), $f_{i}$ is the frequency of $i^{t h}$ genotype, $\mu$ is the population mean that can

Table 1. The means and standard deviations for blood components measured in $F_{2}$ individuals from the cross between Korean native pig (KNP) and Yorkshire (YK)

\begin{tabular}{|c|c|c|c|c|c|c|}
\hline Trait & $\mathrm{N}$ & Mean & SD & Minimum & Maximum & $\mathrm{CV}^{\mathrm{a}}$ \\
\hline Neutrophil (mg/dl) & 209 & 54.1 & 13.0 & 7 & 85 & 30.9 \\
\hline Lymphocyte (mg/dl) & 209 & 41.2 & 12.7 & 11 & 86 & 65.7 \\
\hline Monocyte (mg/dl) & 209 & 3.7 & 2.4 & 0 & 12 & 257.4 \\
\hline Eosinophil (mg/dl) & 209 & 0.3 & 0.9 & 0 & 8 & 427.6 \\
\hline Basophil (mg/dl) & 209 & 0.1 & 0.3 & 0 & 2 & 168.5 \\
\hline Atypical lymph (mg/dl) & 209 & 0.6 & 1.0 & 0 & 6 & 71.4 \\
\hline Immuno globulin (g/dl) & 217 & 2.0 & 0.4 & 1 & 4 & 24.0 \\
\hline Insulin $(\mu \mathrm{IU} / \mathrm{ml})$ & 217 & 7.0 & 5.6 & 2 & 35 & 15.4 \\
\hline Insulin-like growth factor-I (ng/ml) & 217 & 198.2 & 71.3 & 715 & 534 & 79.4 \\
\hline
\end{tabular}

${ }^{a}$ Coefficient of variation: $100 \times \mathrm{SD} /$ mean. 
be expressed as $\left(f_{A A}-f_{B B}\right) \hat{a}$ (Falconer and Mackay, 1996). Proportion of phenotypic variance due to the $j^{\text {th }}$ SNP was then estimated as $S_{S N P j}^{2} / S_{p}^{2}$, in which $S_{p}^{2}$ was obtained from residual values of the trait after adjusting fixed and/or covariate effects. Therefore, the estimate of the proportion of phenotype variance due to all of the significant SNPs was $\sum S_{S N P j}^{2} / S_{P}^{2}$.

\section{RESULTS AND DISCUSSION}

A set of 46,865 SNPs was chosen from the 62,163 SNPs in Illumina Porcine SNP 60K Beadchip (Table 2). The number of SNPs $(6,622)$ was the greatest in Sus scrofa chromosome (SSC) 1, while SSC12 had the smallest number of SNPs (1,098). The SSCs 4, 7, 13, and 14 had more than 3,000 SNPs. The physical map with all of the available SNPs spanned about 2,424 Mb with an average distance of $54.0 \pm 143.6 \mathrm{~Kb}$ between adjacent SNPs. However, the average distances were very variable between chromosomes, ranging from $35.6 \mathrm{~Kb}$ in SSC17 to $87.3 \mathrm{~Kb}$ in SSC6. Only $75 \%$ of the SNPs that were embedded in the porcine chip were available in this study, partly due to ascertainment bias, i.e. the Illumina porcine SNP $60 \mathrm{~K}$ Beadchip was not based on the genetics of Korean native pigs, but other commercial breeds.

A total of 54 SNPs were detected in various chromosomes by the stepwise regression procedures, and the SNPs for each trait explained great proportions of phenotypic variance, ranging from $24 \%$ for eosinophil to $42 \%$ for neutrophil (Table 3).
The white blood cell (WBC) components such as neutrolphil, lymphocyte, monocyte, eosinophil, and basophil, are essential for immune responses in mammalian species. We identified ten SNP (QTL) for neutrophil on SSCs $1,4,8,11,13,14$ and 15 in a $\mathrm{KNP} \times \mathrm{YK}$ cross population (Table 3). Among the QTL, three QTL on SSCs 4, 13 and 14 had pleiotropic effects, i.e. for lymphocyte, for which additional three QTL were detected on SSC1, 11, and 18 (Table 3). For monocytes, four QTL were detected on SSCs 4, 5, 6 and 10, and for eosinophils four significant SNPs on SSCs 2, 4, 11 and 15 (Table 3). A total of five QTL for basophil were found, among which the QTL on SSC13 was resided closely with the lymphocytes QTL (Table 3).

Neutrophil, a leukocyte WBC component, engulfs, kills and digests microorganisms. Interleukins or other cytokines are, in general, produced in lymphocytes or monocytes. Li et al. (2010) reported that a QTL for neutrophil was found at $29.8 \mathrm{cM}$ on SSC1 in Landrace, while we detected a neutrophil QTL at $30.8 \mathrm{Mb}$ (Table 3). A protein coding gene, MAP3K5, was located around the QTL (Ensembl). DARC gene, which was reported to regulate neutrophil production and migration in human (Dawson et al., 2000; Lee et al., 2006; Reutershan et al., 2009; Schnabel et al., 2010; Reiner et al., 2011), resides at $99 \mathrm{Mb}$ on SSC4 in pig genome. We detected a neutrophil QTL at $106 \mathrm{Mb}$ on the same chromosome (Table 3). For the same trait, Reiner et al. (2008) reported two QTL in a Meishan $\times$ Pietrain cross, which were located at $8 \mathrm{cM}$ on SSC4 and at $23 \mathrm{cM}$ on SSC11, respectively. In the similar regions, two QTL were detected at $17 \mathrm{Mb}$ and $18 \mathrm{Mb}$ in the respective

Table 2. The numbers of available SNPs and average interval distance between flanking SNPs across all 18 autosomes (SSC) in the $\mathrm{KNP} \times \mathrm{YK} \mathrm{F}_{2}$ population

\begin{tabular}{|c|c|c|c|c|}
\hline $\mathrm{SSC}$ & Number of SNPs & Average interval size $(\mathrm{kb})$ & $\mathrm{SD}(\mathrm{kb})$ & Total distance (bp) \\
\hline 1 & 6,622 & 44.6 & 133.5 & $295,554,054$ \\
\hline 2 & 2,677 & 57.3 & 169.2 & $153,324,765$ \\
\hline 3 & 2,178 & 67.1 & 201.1 & $146,204,919$ \\
\hline 4 & 3,693 & 39.1 & 90.2 & $144,452,577$ \\
\hline 5 & 2,257 & 45.9 & 141.2 & $103,518,423$ \\
\hline 6 & 1,967 & 87.3 & 236.3 & $171,673,133$ \\
\hline 7 & 3,554 & 37.5 & 34.9 & $133,307,931$ \\
\hline 8 & 2,224 & 67.5 & 168.1 & $149,995,098$ \\
\hline 9 & 2,638 & 58.5 & 189.8 & $154,365,393$ \\
\hline 10 & 1,363 & 57.0 & 182.5 & $77,744,768$ \\
\hline 11 & 1,862 & 45.2 & 111.3 & $84,223,424$ \\
\hline 12 & 1,098 & 62.2 & 170.1 & $68,252,608$ \\
\hline 13 & 3,633 & 59.9 & 168.9 & $217,637,564$ \\
\hline 14 & 4,056 & 36.7 & 28.6 & $148,678,088$ \\
\hline 15 & 2,659 & 63.7 & 204.8 & $169,455,966$ \\
\hline 16 & 1,574 & 55.5 & 168.4 & $87,281,785$ \\
\hline 17 & 1,672 & 35.6 & 56.9 & $59,523,835$ \\
\hline 18 & 1,138 & 51.8 & 129.2 & $58,905,756$ \\
\hline Total & 46,865 & Average & Average & $2,424,100,087$ \\
\hline
\end{tabular}


Table 3. Identities, positions, and effects of the SNPs associated with blood component traits in a KNP $\times Y K$ cross population

\begin{tabular}{|c|c|c|c|c|c|c|c|c|}
\hline Trait/SNP marker ${ }^{\mathrm{a}}$ & $\mathrm{SNP}^{\mathrm{b}}$ & SSC & $\mathrm{Kb}^{\mathrm{c}}$ & $\mathrm{MAF}^{\mathrm{d}}$ & $-\log _{10} \mathrm{P}^{\mathrm{e}}$ & Estimate $^{f}$ & $\mathrm{SE}^{\mathrm{g}}$ & $\% \sigma_{p}^{2 h}$ \\
\hline Neutrophil & & & & & & & & 42.09 \\
\hline INRA0001776 & [G/A] & 1 & 30,834 & 0.09 & 3.24 & 10.49 & 1.68 & 9.54 \\
\hline ALGA0023828 & {$[\mathrm{T} / \mathrm{C}]$} & 4 & 17,218 & 0.28 & 4.15 & -4.94 & 1.07 & 5.21 \\
\hline ASGA0021917 & {$[\mathrm{T} / \mathrm{C}]$} & 4 & 106,241 & 0.06 & 3.53 & 7.20 & 1.94 & 3.36 \\
\hline ALGA0047025 & [G/A] & 8 & 10,470 & 0.13 & 3.02 & -4.91 & 1.47 & 2.86 \\
\hline ASGA0050232 & {$[\mathrm{C} / \mathrm{T}]$} & 11 & 17,682 & 0.37 & 3.46 & 3.28 & 0.95 & 3.05 \\
\hline DRGA0011174 & [G/A] & 11 & 31,631 & 0.06 & 3.51 & 7.30 & 1.91 & 3.56 \\
\hline ALGA0063379 & {$[\mathrm{A} / \mathrm{G}]$} & 11 & 55,046 & 0.41 & 3.03 & 3.27 & 0.99 & 2.64 \\
\hline ALGA0067602 & {$[\mathrm{A} / \mathrm{G}]$} & 13 & 3,570 & 0.50 & 4.65 & 2.81 & 0.99 & 2.13 \\
\hline M1GA0019807 & [G/A] & 14 & 145,639 & 0.26 & 3.64 & -3.64 & 1.19 & 2.35 \\
\hline H3GA0045535 & {$[\mathrm{G} / \mathrm{A}]$} & 15 & 93,065 & 0.33 & 4.11 & 5.36 & 0.99 & 7.40 \\
\hline Lymphocyte & & & & & & & & 28.91 \\
\hline ALGA0003271 & {$[\mathrm{T} / \mathrm{C}]$} & 1 & 42,786 & 0.10 & 5.57 & 7.73 & 1.82 & 5.85 \\
\hline ALGA0023828 & {$[\mathrm{T} / \mathrm{C}]$} & 4 & 17,218 & 0.28 & 4.52 & 4.93 & 1.21 & 5.39 \\
\hline H3GA0032363 & {$[\mathrm{C} / \mathrm{T}]$} & 11 & 55,220 & 0.30 & 3.05 & -3.59 & 1.19 & 3.08 \\
\hline ALGA0067602 & {$[\mathrm{A} / \mathrm{G}]$} & 13 & 3,570 & 0.50 & 4.80 & -5.02 & 1.11 & 7.09 \\
\hline M1GA0019807 & [G/A] & 14 & 145,639 & 0.26 & 3.14 & 4.28 & 1.31 & 3.37 \\
\hline ASGA0079719 & {$[\mathrm{A} / \mathrm{G}]$} & 18 & 24,680 & 0.21 & 3.31 & 4.67 & 1.32 & 4.14 \\
\hline Monocyte & & & & & & & & 26.65 \\
\hline ALGA0024578 & {$[\mathrm{C} / \mathrm{T}]$} & 4 & 33,041 & 0.47 & 3.32 & 0.87 & 0.22 & 6.29 \\
\hline ASGA0023933 & {$[\mathrm{C} / \mathrm{A}]$} & 5 & 2,659 & 0.06 & 3.70 & -1.71 & 0.44 & 5.59 \\
\hline ALGA0037265 & [G/A] & 6 & 38,645 & 0.20 & 3.64 & 1.26 & 0.26 & 9.26 \\
\hline H3GA0055101 & {$[\mathrm{C} / \mathrm{T}]$} & 10 & 194 & 0.42 & 3.65 & 0.83 & 0.22 & 5.50 \\
\hline Eosinophil & & & & & & & & 24.98 \\
\hline DRGA0003276 & {$[\mathrm{C} / \mathrm{T}]$} & 2 & 52,733 & 0.07 & 3.85 & -0.63 & 0.15 & 6.55 \\
\hline M1GA0006491 & {$[\mathrm{A} / \mathrm{G}]$} & 4 & 114,767 & 0.25 & 4.19 & 0.34 & 0.09 & 5.98 \\
\hline MARC0001377 & [G/A] & 11 & 39,551 & 0.39 & 3.56 & -0.33 & 0.08 & 7.11 \\
\hline ASGA0070239 & {$[\mathrm{C} / \mathrm{G}]$} & 15 & 70,085 & 0.08 & 3.41 & 0.52 & 0.15 & 5.34 \\
\hline Basophil & & & & & & & & 26.82 \\
\hline INRA0004984 & [G/A] & 1 & 140,664 & 0.29 & 3.08 & -0.08 & 0.03 & 3.72 \\
\hline MARC0055620 & {$[\mathrm{C} / \mathrm{T}]$} & 2 & 69,303 & 0.06 & 5.84 & -0.22 & 0.05 & 5.80 \\
\hline ALGA0067658 & [G/A] & 13 & 4,270 & 0.10 & 3.21 & -0.17 & 0.04 & 6.45 \\
\hline ASGA0060375 & {$[\mathrm{T} / \mathrm{G}]$} & 14 & 865 & 0.33 & 3.02 & 0.08 & 0.03 & 4.40 \\
\hline MARC0052349 & {$[\mathrm{A} / \mathrm{G}]$} & 16 & 42,368 & 0.10 & 3.00 & 0.17 & 0.04 & 6.45 \\
\hline Atypical Lymph & & & & & & & & 29.47 \\
\hline DIAS0003279 & {$[\mathrm{A} / \mathrm{G}]$} & 4 & 65,959 & 0.31 & 4.25 & -0.51 & 0.11 & 9.08 \\
\hline ALGA0029239 & {$[\mathrm{T} / \mathrm{G}]$} & 4 & 120,981 & 0.27 & 4.77 & 0.46 & 0.10 & 7.16 \\
\hline ALGA0033066 & {$[\mathrm{A} / \mathrm{C}]$} & 5 & 56,650 & 0.43 & 3.30 & 0.42 & 0.09 & 7.81 \\
\hline MARC0057515 & [G/A] & 7 & 108,793 & 0.13 & 3.78 & -0.51 & 0.13 & 5.42 \\
\hline Immuno globulin & & & & & & & & 25.37 \\
\hline ASGA0030288 & {$[\mathrm{A} / \mathrm{G}]$} & 6 & 44,238 & 0.15 & 3.61 & -0.20 & 0.05 & 5.34 \\
\hline H3GA0021269 & {$[\mathrm{A} / \mathrm{G}]$} & 7 & 44,938 & 0.26 & 4.59 & 0.14 & 0.04 & 4.35 \\
\hline CASI0008911 & [G/A] & 13 & 129,859 & 0.17 & 3.58 & -0.20 & 0.05 & 5.52 \\
\hline ASGA0070402 & {$[\mathrm{A} / \mathrm{G}]$} & 15 & 76,723 & 0.40 & 3.02 & -0.12 & 0.04 & 3.98 \\
\hline ASGA0076724 & {$[\mathrm{A} / \mathrm{C}]$} & 17 & 32,707 & 0.48 & 4.17 & -0.15 & 0.03 & 6.18 \\
\hline
\end{tabular}

chromosomes (Table 3). In the proximal region of SSC11, Uddin et al. (2011) reported a QTL $(14 \mathrm{cM})$ for cytokines interleukin 2 (IL2) in a Duroc $\times$ Pietrain cross population, when the individuals were induced by Mycoplasma hypopneumoniae vaccine. They also found two QTL at 35
$\mathrm{cM}$ and $50 \mathrm{cM}$ on SSC11 for IFNG (interferon-gamma) influencing monocyte stimulation, and two TLR9 QTL at 28 cM on SSC11 and at $142 \mathrm{cM}$ on SSC14, respectively. In the similar regions, we detected two neutrophil QTL (Table 3).

For lymphocyte, Reiner et al. (2008) found three QTL at 
Table 3. Identities, positions, and effects of the SNPs associated with blood component traits in a KNP $\times$ YK cross population (Continued)

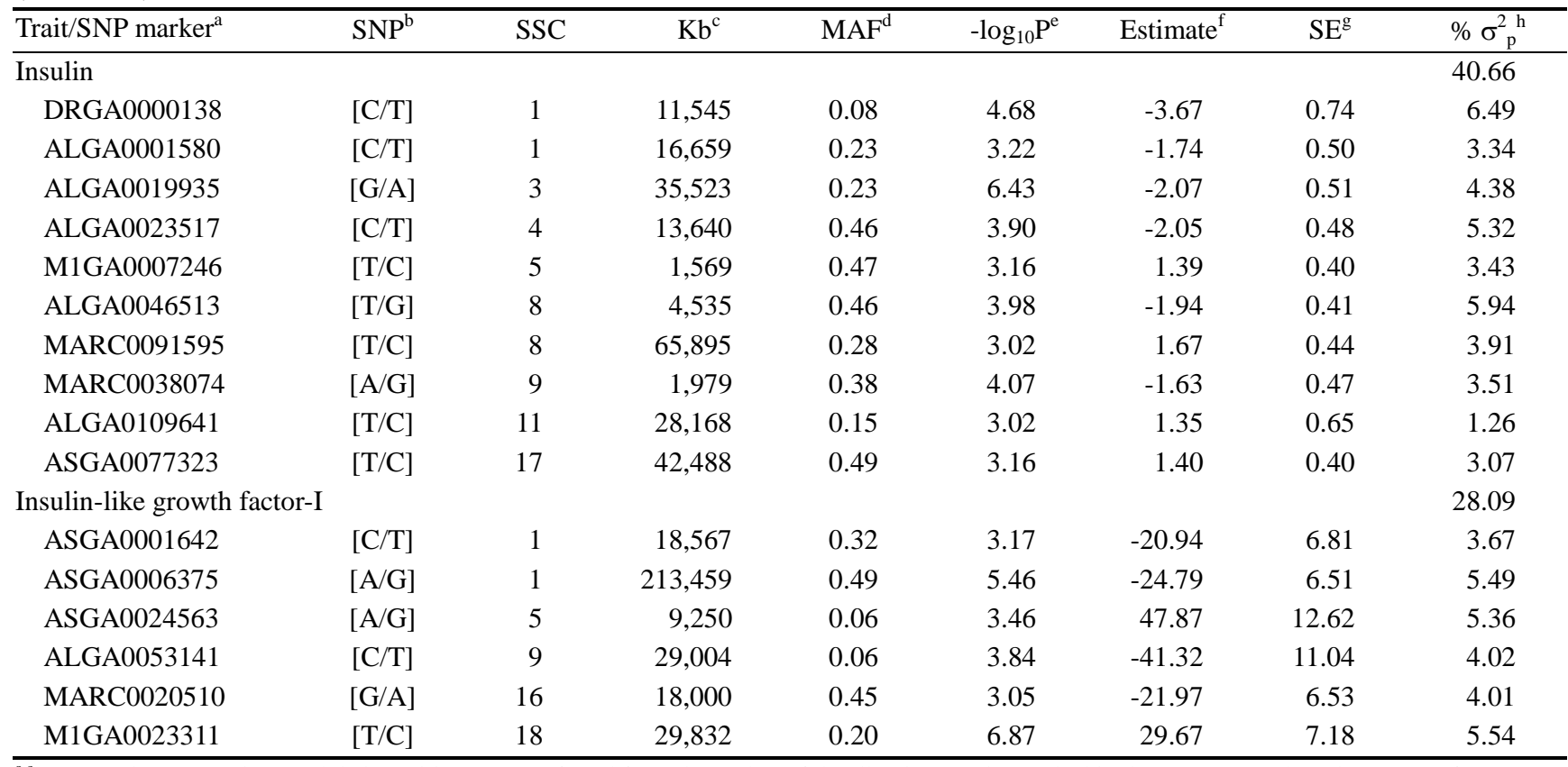

${ }_{\mathrm{a}, \mathrm{c}}$ SNP marker annotations and their positions were referred from the probes of the Illumina porcine $60 \mathrm{k}$ chip that was mapped on the Sus scrofa 9.0.

${ }^{\mathrm{b}}$ Nucleotides of substitution. ${ }^{\mathrm{d}}$ Minor allele frequency. The first letter of the SNP indicates minor allele.

${ }^{\mathrm{e}}$ Negative logarithm of the comparison-wise $\mathrm{p}$ value of the test statistic against the null hypothesis of no SNP effect at the SNP position.

${ }^{\mathrm{f}}$ Estimate is for the allele substitution effect of replacing the latter with the former allele (nucleotide) in the SNP column. ${ }^{\mathrm{g}}$ Standard error.

${ }^{\mathrm{h}}$ Proportion of phenotypic variance explained by the SNP. The values on the rows of trait names are the sum of the $\% \sigma_{\mathrm{p}}^{2}$ values across all SNPs for the trait.

$62 \mathrm{cM}$ on SSC1, at $138 \mathrm{Mb}$ near SW761 on SSC14, and at $29 \mathrm{cM}$ on SSC18, respectively, in a Meishan $\times$ Pietrain cross population. In the similar regions $(43 \mathrm{Mb}, 146 \mathrm{Mb}$, and 25 $\mathrm{Mb}$ ), we detected QTL for lymphocyte (Table 3). Wattrang et al. (2005) reported a QTL for CD2+/CD8+ leukocyte in the S0008 marker region (43.5 to $89.2 \mathrm{cM}$ in PigQTLbd) on SSC1 in the European Wild Boar, Landrace and Yorkshire crosses, while a lymphocyte QTL was detected at $43 \mathrm{Mb}$ in this study. Li et al. (2010) found one QTL for lymphocytes at $29.8 \mathrm{cM}$ on SSC1 in Landrace pigs, while we detected a lymphocyte QTL at $43 \mathrm{Mb}$ on the same chromosome (Table 3).

A few QTL for monocytes were detected in this study. Lu et al. (2011) reported a QTL for $C D+/ C D 8+$ at $1 \mathrm{cM}$ on SSC5 in Landrace, white boar and Songliao Black pig families, while a QTL for monocyte was detected at 2.6 Mb in the KNP x Landrace cross (Table 3). Uddin et al. (2011) reported a QTL for $I L 10$ at $73 \mathrm{cM}$ on SSC6, which was flanked by SW1067 and SW193 (35.8 to 44.2 Mb in Ensembl). In the region, a QTL for monocytes was detected at $39 \mathrm{Mb}$ in this study.

For eosinophil, which acts mainly against parasites, four QTL were detected in this study (Table 3). Reiner et al. (2007) reported an eosinophil QTL at $69 \mathrm{cM}$ on SSC11 flanked by S0182 and SW903 (33 to $77 \mathrm{cM}$ ) in a European Pietrain $\times$ Chinese Meishan cross, in which we detected a
QTL for the trait $(40 \mathrm{Mb})$. In the similar region, Uddin et al. (2011) also found a QTL for TLR2 at $38 \mathrm{cM}$ (SW2008S0071 between 14 and $42 \mathrm{Mb}$, Ensembl).

Yang et al. (2009) reported a QTL for WBC at $63.8 \mathrm{cM}$ on SSC2 in a White Duroc $\times$ Erhualian cross. We detected one QTL for basophil, which is an anti-parasitic and anticoagulant component, at $69 \mathrm{Mb}$ on the same chromosome. Uddin et al. (2010; 2011) reported QTL for TLR9, an immunity related element in gut, at 0 to $47 \mathrm{cM}$ and for $I F N G$ at 47 to $93 \mathrm{cM}$ on SSC16 in a Duroc $\times$ Pietrain cross, where the QTL for basophil was also detected at $42 \mathrm{Mb}$ in this study (Table 3).

Reiner et al. (2002) reported a QTL for a pseudo-rabies resistance/susceptibility QTL at $42 \mathrm{cM}$ on SSC6 in Large White Boars and Meishan sows. We detected one QTL for immunoglobulin ( $\mathrm{Ig}$ ) at $44 \mathrm{Mb}$ on the same chromosome (Table 3). In the similar region, Edfors-Lilja et al. (1998) found a QTL for anti-O149 E. coli, i.e. at $67 \mathrm{cM}$ on SSC6, in a wild boar and Yorkshire cross. Uddin et al. (2010) found Mycoplasma hyopneumoniae antibody titer change due to two QTL on SSC7 $(30.2 \mathrm{cM})$ and SSC15 (83.2 cM) in a Duroc $\times$ Pietrain cross, while two QTL for $\mathrm{Ig}$ were detected at $45 \mathrm{Mb}$ and $77 \mathrm{Mb}$ at the respective chromosomes in this study (Table 3). Ji et al. (2011) reported a QTL for enterotoxigenic E. Coli susceptibility at $89.9 \mathrm{cM}$ on SSC13 ( 140 Mb; PigQTLdb) in a White 
Duroc $\times$ Erhualian $\mathrm{F}_{2}$ cross, while an Ig QTL was located at $130 \mathrm{Mb}$ in this study (Table 3).

$\mathrm{Lu}$ et al. (2011) reported two QTL for CD4+/CD8+ lymphocytes at $73 \mathrm{cM}$ and $124 \mathrm{cM}$ on SSC4 and SSC7, respectively, in Landrace, white boar and Songliao Black pig families. We detected two QTL for atypical lymph at 66 $\mathrm{Mb}$ and $109 \mathrm{Mb}$ on the respective chromosomes (Table 3). Reiner et al. (2007) reported one QTL for platelets at $36 \mathrm{cM}$ on SSC3 in an European Pietrain $\times$ Chinese Meishan cross, while we detected one QTL for insulin at $35 \mathrm{Mb}$ on the same chromosome (Table 3 ).

We detected three QTL for Ig at $32 \mathrm{Mb}$ on SSC17, for insulin at $42 \mathrm{Mb}$ on SSC17, and for monocyte at $33 \mathrm{Mb}$ on SSC4, while Reiner et al. (2007) reported two eosinophil QTLs (at $26 \mathrm{cM}$ and $41 \mathrm{cM}$ ) and one IgG1 QTL in the similar regions of this study. Lu et al. (2011) also found QTL for lymphocytes nearby the insulin like growth factor and for Insulin on SSC16 (18 Mb) and SSC8 (65.9 Mb), respectively. The lymphocytes QTL in Li et al. (2010) was located at $29.8 \mathrm{cM}$ on SSC1, which was closely located to the lymphocyte QTL in this study (Table 3).

Cytokines and TLRs influence each other and it is no wonder of a pleiotropic effect since cytokines and TLRs interact in complex networks (Uddin et al., 2011). TLR9 and TLR2 signaling together account for MyD88-dependent control of parasitemia (Bafica et al., 2006). Therefore, closer locations of TLRs and IL2 QTLs along with WBC QTLs may be an active region, which is involved in execution of a large dependent complex mechanism to build up the innate and acquired immunity of an individual.

However, few QTL for immune components were confirmed in this study, which were previously reported at the same or similar chromosomal regions in other studies on immunity QTL. This may be partly due to breed differences, as the baseline immune response and performance traits are affected by breeds (Sutherland et al., 2005). Further QTL studies are, thus, needed to verify the detected QTL for immune response and to identify causal genes to apply to pig health breeding programs with greater efficiency and accuracy.

\section{CONCLUSION}

Selection program for immunity has not been extensively implemented in pig industry. In this study, 54 QTL (SNPs) were detected for nine blood component traits with significant contributions to the phenotypic variances. These QTL would provide a set of genetic markers to implement marker-assisted selection (MAS), which would enable genetic improvement on immunity through pig health breeding programs.

\section{ACKNOWLEDGEMENT}

This work was supported by grants from the NextGeneration BioGreen 21 Program (No. PJ008089).

\section{REFERENCES}

Bafica, A., H. C. Santiago, R. Goldszmid, C. Ropert, R. T. Gazzinelli and A. Sher. 2006. Cutting edge: TLR9 and TLR2 signaling together account for Myd88-dependent control of parasitemia in trypanosoma cruzi infection. J. Immunol. 177:3515-3519.

Coates, M. E., R. Fuller, G. F. Harrison, M. Lev and S. F. Suffolk. 1963. Comparison of the growth of chicks in the Gustafsson germ-free apparatus and in a conventional environment, with and without dietary supplements of penicillin. Br. J. Nutr. 17:141-151.

Cho, I. C., H. B. Park, C. K. Yoo, G. J. Lee, H. T. Lim, J. B. Lee, E. J. Jung, M. S. Ko, J. H. Lee and J. T. Jeon. 2011. QTL analysis of white blood cell, platelet and red blood cell-related traits in an F2 intercross between Landrace and Korean native pigs. Anim. Genet. 42:621-626.

Danilowicz, E., M. Akouchekian, C. Drogemuller, B. Haase, T. Leeb, H. Kuiper, O. Distl and F. C. Iras. 2008. Molecular characterization and SNP development for the porcine IL6 and ILIO genes. Anim. Biotechnol. 19:159-165.

Dawson, T. C., A. B. Lentsch, Z. Wang, J. E. Cowhig and A. Rot. 2000. Exaggerated response to endotoxin in mice lacking the Duffy antigen/receptor for chemokines (DARC). Blood 96: 1681-1684

Edfors-Lilja, I., E. Wattrang, L. Marklund, M. Moller, L. Andersson-Eklund, L. Andersson and C. Fossum. 1998. Mapping quantitative trait loci for immune capacity in the pig. J. Immunol. 161:829-835.

Falconer, D. S. and F. C. Mackay. 1996. Introduction to Quantitative Genetics, 4th ed., Longman Group Ltd, England.

Ji, H., J. Ren, X. Yan, X. Huang, B. Zhang, Z. Zhang and L. Huang. 2011. The porcine MUC20 gene: molecular characterization and its association with susceptibility to enterotoxigenic Escherichia coli F4ab/ac. Mol. Biol. Rep. 38:1593-1601.

Kruse, R., B. Essen-Gustavsson, C. Fossum and M. Jensen-Waern. 2008. Blood concentrations of the cytokines IL-1beta, IL-6, IL-10, TNF-alpha and IFN-gamma during experimentally inducedswine dysentery. Acta Vet. Scand. 50:32-39.

Lee, J. S., M. M. Wurfel, G. Matute-Bello, C. W. Frevert and M. R. Rosengart. 2006. The Duffy antigen modifies systemic and local tissue chemokine responses following lipopolysaccharide stimulation. J. Immunol. 177:8086-8094.

Li, Y., S. L. Yang, Z. L. Tang, W. T. Cui, Y. L. Mu, M. X. Chu, S. H. Zhao, Z. F. Wu, K. Li and K. M. Peng. 2010. Expression and SNP association analysis of porcine FBXL4 gene. Mol. Biol. Rep. 37:579-585.

Lu, X., J. F. Liu, Y. F. Gong, Z. P Wang, Y. Liu and Q. Zhang. 2011. Mapping quantitative trait loci for $\mathrm{T}$ lymphocyte subpopulations in peripheral blood in swine. BMC Genet. 12:79-88

Neter, J., W. Wasserman and M. H. Kutner. 1990. Applied linear 
statistical models. 3rd ed. Irwin. Boston, USA

Reiner, G., E. Melchinger, M. Kramarova, E. Pfaff, M. Buttner, A Saalmuller and H. Geldermann. 2002. Detection of quantitative trait loci for resistance/susceptibility topseudorabies virus in swine. J. Gen. Virol. 83:167-172.

Reiner, G., D. Kliemt, H. Willems, T. Berge, R. Fischer, F. Köhler, S. Hepp, B. Hertrampf, A. Daugschies, H. Geldermann, U. Mackenstedt and H. Zahner. 2007. Mapping of quantitative trait loci affecting resistance/susceptibility to Sarcocystis miescheriana in swine. Genomics 89:638-646.

Reiner, G., R. Fischer, S. Hepp, T. Berge, F. Köhler and H. Willems. 2008. Quantitative trait loci for white blood cell numbers in swine. Anim. Genet. 39:163-168.

Reiner, A. P., G. Lettre, M. A. Nalls, S. K. Ganesh and R. Mathias 2011. Genome-Wide association study of white blood cell count in 16,388 African Americans: the continental origins and genetic epidemiology network (COGENT). PLoS Genet. 7: e1002108.

Reutershan, J., B. Harry, D. Chang, G. J. Bagby and K. Ley. 2009. DARC on RBC limits lung injury by balancing compartmental distribution of CXC chemokines. Eur. J. Immunol. 39:15971607.

Roura, E., J. Homedes and K. C. Klasing. 1992. Prevention of immunologic stress contributes to the growth-permitting ability of dietary antibiotics in chicks. J. Nutr. 122:2383-2390.

Scheerlinck, J. P. and H. H. Yen. 2005. Veterinary applications of cytokines. Vet. Immunol. Immunopathol. 108:17-22.

Schnabel, R. B., J. Baumert, M. Barbalic, J. Dupuis and P. T. Ellinor. 2010. Duffy antigen receptor for chemokines (Darc) polymorphism regulates circulating concentrations of monocyte chemoattractant protein-1 and other inflammatory mediators. Blood 115:5289-5299.
Shinkai, H., M. Tanaka, T. Morozumi, T. Eguchi-Ogawa, N. Okumura, Y. Muneta, T. Awata and H. Uenishi. 2006. Biased distribution of single nucleotide polymorphisms (SNPs) in porcine Toll-like receptor 1 (TLR1), TLR2, TLR4, TLR5, and TLR6 genes. Immunogenetics 58:324-330.

Sutherland, M. A., S. L. Rodriguez-Zas, M. Ellis and J. L. SalakJohnson. 2005. Breed and age affect baseline immune traits, cortisol, and performance in growing pigs. J. Anim. Sci. 83:2087-2095.

Uddin, M. J., M. U. Cinar, C. Grosse-Brinkhaus, D. Tesfaye, E. Tholen, H. Juengst, C. Looft, K. Wimmers, C. Phatsara and K. Schellander. 2011. Mapping quantitative trait loci for innate immune response in the pig. Immunogenetics 38:121-131.

Uddin, M. J., C. Grosse-Brinkhaus, M. U. Cinar, E. Jonas, D. Tesfaye, E. Tholen, H. Juengst, C. Looft, S. Ponsuksili, K. Wimmers and C. S. Phatsara. 2010. Mapping of quantitative trait loci for mycoplasma and tetanus antibodies and interferon-gamma in a porcine F2 Duroc $\times$ Pietrain resource population. Mamm. Genome 21:409-418.

Uenishi, H. and H. Shinkai. 2009. Porcine Toll-like receptors: the front line of pathogen monitoring and possible implications for disease resistance. Dev. Comp. Immunol. 33:353-361.

Wattrang, E., M. Almqvist, A. Johansson, C. Fossum, P. Wallgren, G. Pielberg, L. Andersson and I. Edfors-Lilja. 2005. Confirmation of QTL on porcine chromosomes 1 and 8 influencing leukocyte numbers, haematological parameters and leukocyte function. Anim. Genet. 36:337-345.

Yang, S., J. Ren, X. Yan, X. Huang, Z. Zou, Z. Zhang, B. Yang and L. Huang. 2009. Quantitative trait loci for porcine white blood cells and platelet-related traits in a White Duroc $\times$ Erhualian F resource population. Anim. Genet. 40:273-278.

Yao Q., Q. Huang, Y. Cao, P. Qian and H. Chen. 2008. Porcine interferongamma protects swine from foot-and-mouth disease virus (FMDV). Vet. Immunol. Immunopathol. 122:309-311. 